\title{
Preliminary Research on Influence of Welding Parameters Strength at Welded Joints in Ribbed Reinforcing Steel
}

\author{
Željko Bilić, Ivan Samardžić, Nedjeljko Mišina, Katarina Stoić*
}

\begin{abstract}
As already known, no proper control or process control parameter which absolutely guarantees a high level quality of joints made by electro-resistive welding has been established so far, especially when all possible parameters are taken into account during the welding process. Due to the process of butt-welding being very short-lived, ensuring quality of the joints is a difficult and under-researched problem. The application of non-destructive testing methods to the control interface joints is also not reliable. Therefore, further research in this area should concentrate on studying the influence of basic welding parameters, and calculating their direct or indirect impact can serve to achieve a highquality welded joint with for practice sufficient accuracy.
\end{abstract}

Keywords: intensity and time passage of welding current; pressure force upon sealing; tensile strength of welded joint

\section{INTRODUCTION}

Obtaining a quality welded joint involves the determination and finding of the optimal relationship between a large number of parameters, which is very difficult, if not impossible to take into account in real production conditions. All of these parameters are interdependent and changing; one parameter can cause the value of several other parameters to change, which makes them very complex to study. In practice, all influential quantities that disturb the stability of the process are not considered, whereas only those with the greatest impact are [2].

Generally, by taking the Z-side welding process we can think of a set to which sets of input sizes $(x)$ and output sizes (y) are connected, Fig. 1.

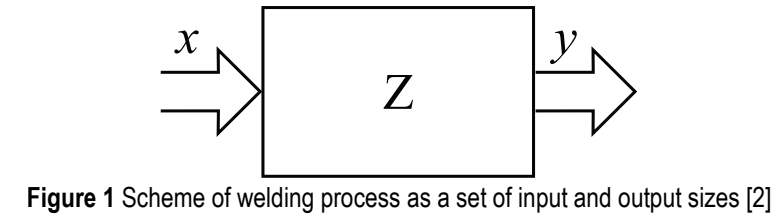

In this case, the dependence between input sizes $(x)$ and output sizes $(y)$ can be represented analytically, in tables or graphically. If in our considerations we denote the selected size (quality criterion) by $(y)$, and the set of input variables (basic parameters of the welding mode) by $(x)$ then the dependence $y=y(x)$ can be written in the following form:

$y=f\left(x_{i}\right) ; i=1,2,3, \ldots, n$

All analytical expressions, tables or curves that show this dependence are called mathematical models in which time changes of the chosen parameters do not occur; thus, they are called static models described by algebraic expressions [2].

The quality of the welded joint is an integral category and can be discussed in several aspects. Welding result is a quantitative measure that captures the mechanical properties of a welded joint. To determine these characteristics, welds should be tested by non-destructive methods. Testing of welds by such methods is performed on specimens whose shape and dimensions depend on the purpose of the test. This test group includes tests of mechanical properties:

- testing the tensile strength and breaking strength of the welded joint,

- welding joint welding test,

- microscopic examination to determine the geometric characteristics of the weld,

- dynamic testing.

The non-destructive testing group used in concrete steels includes radiographic, ultrasonic and visual testing.

The quality criterion is usually taken to be the breaking tensile force $F_{\mathrm{M}}$; however, the tensile strength of the welded joint can also be taken. It is also possible to determine the character of the change in tensile strength by measuring the hardness per section of the weld. Due to the limitations of the testing machine, the following quality requirements will be taken into account as a quality criterion in these studies, and according to previous considerations [2]:

- tensile limit of welded joint $\sigma_{\mathrm{R}}(\mathrm{MPa})$,

- tensile strength of welded joint $\sigma_{\mathrm{M}}(\mathrm{MPa})$,

- breaking force of welded joint $F_{\mathrm{M}}(\mathrm{kN})$.

\section{DEFINING BASIC WELDING PARAMETERS}

From the very expression of Joule law, which defines the decisive factors of the thermal phenomenon of butt-welding:

$Q=\int_{0}^{t} I^{2}(t) \cdot R(t) \mathrm{d} t$

where: $I$ - current (A); $R$ - electrical resistance $(\Omega) ; t$ - time passage of electric current (s).

It can be concluded that the process of forming a welded joint is decisively influenced by: current $(I)$, time of passage of current through welded pieces $(t)$ and electrical resistance of a part of the secondary circuit between the electrodes $(R)$. 
The above expression does not explicitly take into account the pressure force between the welding pieces, which is one of the important factors in the butt-welding process. The mechanism formation of the butt-weld is quite complex, both from thermal and metallurgical aspect, and it is logical to ask under what conditions optimal quality of the joint will be obtained, i.e. what relation should be established between the above and some other welding parameters in order to achieve the desired target. It can be said that in order to obtain a quality welded joint, an optimal relationship should be established between:

- the strength of the welding current and the time it flows through the welded pieces,

- the magnitude of the pressure force between the workpieces and its time change,

- types of materials.

The following parameters should definitely be added: shape of the current wave (heating, cooling) and times of different stages in the welding cycle (intermission, time of pressure setting, etc.). All these parameters are selected on the welding machine, but the quality of the welded joint is also influenced by the properties of the material that we want to weld, such as:

- thickness of welded pieces and their shape,

- condition of contact surfaces on the piece,

- mechanical properties of welded pieces,

- chemical composition of the material,

- electrical resistance of the material,

- thermal conductivity of the material,

- some important physical characteristics of the material being welded,

- metallurgical properties of materials.

Some of the listed properties significantly affect the quality of the joint. However, since it is a matter of securing materials of a certain shape and thickness, attention is focused on controlling the parameters that are set on the welding machine.

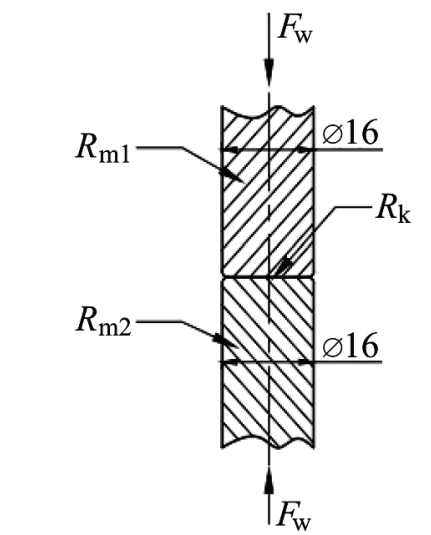

Figure 2 Total resistances for butt welding [2]

The main factors on which the required amount of heat for the formation of a welded joint depends are that the thickness of the welded pieces increases, the current strength also increases, the current time of welding is longer, and the pressure between the electrodes is higher to obtain a quality joint. The process of forming a butt weld is significantly influenced by the condition of the piece through the contact resistances, Fig. 2. The resistor resistance $R_{\mathrm{C}}$ represents the total resistance on the part of the electrical circuit between the workpieces and the sum of the following resistances is shown:

$R_{\mathrm{c}}=R_{\mathrm{m} 1}+R_{\mathrm{k}}+R_{\mathrm{m} 2}$

where: $R_{\mathrm{k}}$ - contact resistances piece - piece, $R_{\mathrm{m} 1}, R_{\mathrm{m} 2}$ intrinsic resistance of welded specimens.

At the initial moment the contact temperature is the highest because most of the Joules heating is released at the contact between the pieces. However, as the temperature increases, the contact resistance $R_{\mathrm{k}}$ decreases, and the resistance value $R_{\mathrm{m} 1}$ and $R_{\mathrm{m} 2}$ increases with increasing temperature, and they now play a greater role. Contact resistance at the point of contact occurs due to inhomogeneity of contact. The metal surface is characterized by greater or lesser roughness, which under microscopic magnification has the shape of a relief. From the cross section of the piece, the roughness is manifested in the form of ridge projections and recesses, Fig. 3.

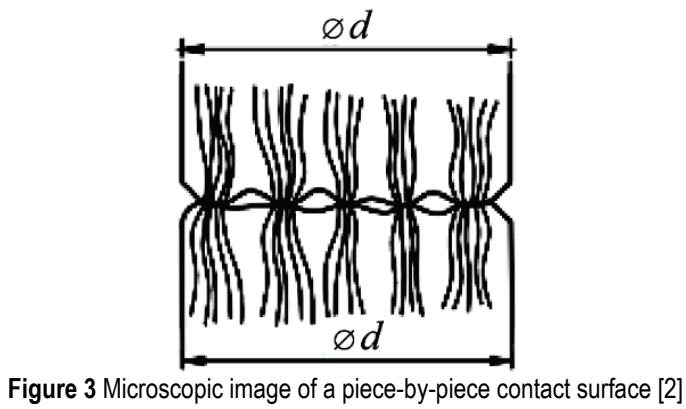

Contact is made only on ridged projections. Therefore, the current flows only through the actual contacts in order to obtain a very high concentration of current on that surface, which leads to a large electrical resistance at the points of contact and results in a high spark during welding.

In principle it can be said that contact resistances depend on:

- contact behavior of metals (mechanical properties, electrical and thermal conductivity),

- state of the surface on the piece (oxides, impurities, oil, grease, etc.),

- the force pressure acting on the pieces,

- metal temperatures at the point of contact.

The latest research to determine the effect of surface roughness or method of surface preparation, which influences the size of the contact resistance when welding concrete steels shows the following:

- the speed of volume expansion on welds increases with reducing the surface roughness and increasing the electrical resistance of steel, 
- the weld ductility increases with decreasing of the roughness at the contact surface on the welded piece.

\section{SELECTION OF CONCRETE STEEL FOR EXPLORATION}

A $16 \mathrm{~mm}$ diameter ribbed concrete bar with DIN 488 BSt $420 \mathrm{~S}$. grade was selected for the study. The bars were first rolled and then heat treated. The chemical composition of the bars and the mechanical properties are shown in Tabs. 1 and 2.
Table 1 Chemical composition of bars $16 \mathrm{~mm}$ in diameter

\begin{tabular}{|c|c|c|c|c|c|c|c|c|c|}
\hline No. & $\mathrm{C}$ & $\mathrm{Si}$ & $\mathrm{Mn}$ & $\mathrm{P}$ & WITH & $\mathrm{Cu}$ & $\mathrm{Cr}$ & $\mathrm{Sn}$ & Nor \\
\hline 1 & 0.33 & 0.24 & 0.88 & 0.03 & 0.04 & 0.40 & 0.14 & 0.02 & 0.11 \\
\hline 2 & 0.29 & 0.28 & 0.90 & 0.04 & 0.05 & 0.45 & 0.18 & 0.05 & 0.18 \\
\hline 3 & 0.30 & 0.28 & 0.94 & 0.03 & 0.07 & 0.58 & 0.14 & 0.04 & 0.16 \\
\hline 4 & 0.30 & 0.32 & 0.93 & 0.03 & 0.05 & 0.74 & 0.19 & 0.04 & 0.20 \\
\hline 5 & 0.33 & 0.25 & 0.85 & 0.04 & 0.06 & 0.51 & 0.12 & 0.02 & 0.09 \\
\hline 6 & 0.33 & 0.28 & 0.93 & 0.04 & 0.05 & 0.43 & 0.17 & 0.02 & 0.13 \\
\hline 7 & 0.35 & 0.24 & 1.00 & 0.04 & 0.05 & 0.44 & 0.20 & 0.03 & 0.13 \\
\hline 8 & 0.36 & 0.22 & 0.94 & 0.06 & 0.04 & 0.56 & 0.17 & 0.03 & 0.11 \\
\hline 9 & 0.28 & 0.25 & 0.87 & 0.04 & 0.05 & 0.61 & 0.14 & 0.03 & 0.11 \\
\hline
\end{tabular}

Table 2 Mechanical properties of bars $16 \mathrm{~mm}$ in diameter

\begin{tabular}{|c|c|c|c|c|c|c|c|c|c|}
\hline \multirow{2}{*}{ No. } & \multirow[b]{2}{*}{ The batch } & \multicolumn{3}{|c|}{ Dimension $(\mathrm{mm})$} & \multirow{2}{*}{$\begin{array}{c}\text { Stretching limit } \\
\mathrm{MPa}\end{array}$} & \multirow{2}{*}{$\begin{array}{c}\text { Tensile strength } \\
\mathrm{MPa} \\
\end{array}$} & \multirow[b]{2}{*}{ Elongation \% } & \multirow[b]{2}{*}{ Flexion } & \multirow[b]{2}{*}{ Weight $\mathrm{kg} / \mathrm{m}$} \\
\hline & & Diameter & Rib height & Width of rib & & & & & \\
\hline 1 & 142914 & 15,30 & 1.6 & 3.4 & 432 & 624 & 25 & 90 & 1550 \\
\hline 2 & 228051 & 15,30 & 1.6 & 3.5 & 441 & 633 & 20 & 90 & 1550 \\
\hline 3 & 228050 & 15,30 & 1.6 & 3.8 & 447 & 643 & 20.6 & 90 & 1560 \\
\hline 4 & 228049 & 15,30 & 1.6 & 3.7 & 452 & 657 & 20 & 90 & 1570 \\
\hline 5 & 142835 & 15,40 & 1.5 & 3.5 & 442 & 638 & 19.4 & 90 & 1590 \\
\hline 6 & 142834 & 15,40 & 1.5 & 3.5 & 460 & 681 & 21.9 & 90 & 1590 \\
\hline 7 & 142833 & 15,30 & 1.9 & 3 & 456 & 676 & 18.8 & 90 & 1580 \\
\hline 8 & 142907 & 15,30 & 1.7 & 3 & 487 & 732 & 18.1 & 90 & 1560 \\
\hline 9 & 142905 & 15,40 & 1.6 & 3.4 & 449 & 655 & 23.1 & 90 & 1590 \\
\hline
\end{tabular}

\section{EXPERIMENT PLANNING AND SELECTION OF EXPERIMENT PARAMETERS}

After selecting $16 \mathrm{~mm}$ diameter steel bars, it was necessary to define a test plan and select parameters according to certain mathematical models. According to [2], a three-factor experiment plan was chosen with two extreme levels for each parameter and at least three repetitions for each combination of parameter levels. Such a three-factor plan of experiments with a mean (zero) level can be shown in coded coordinates in the form of cubes, Fig. 4.

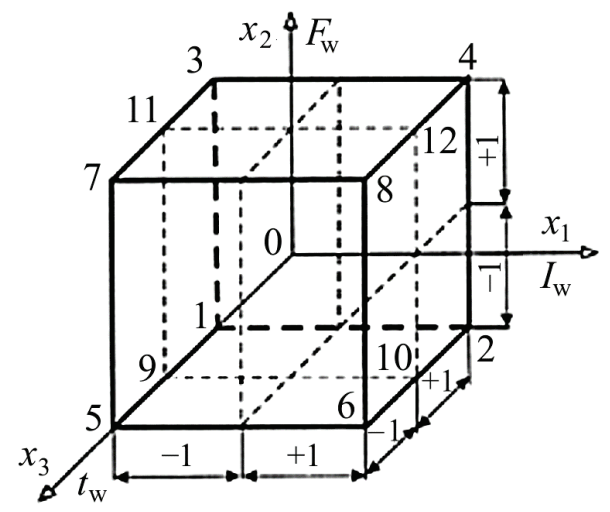

Figure 4 Model of three-factor test plan in coded coordinates $x_{1}, x_{2}, x_{3}[2]$

Number of trials in one batch:

$$
N=2^{n}+n_{0}=2^{3}+4=12 \frac{\text { experiments }}{\text { samples }}
$$

where: $n=3$ - number of factors (welding parameters); $n_{0}$ number of intermediate level experiments introduced to evaluate the adequacy of the mathematical model obtained.
The values of the parameters selected by the three-factor test plan are given in Tab. 3 .

Table 3 Welding parameters selected by three-factor test plan [2]

\begin{tabular}{|c|c|c|c|}
\hline No. & $I_{\mathrm{w}}(\mathrm{A})$ & $F_{\mathrm{w}}(\mathrm{N})$ & $t_{\mathrm{w}}(\mathrm{s})$ \\
\hline 1 & 23 & 150 & 3 \\
\hline 2 & 28 & 150 & 3 \\
\hline 3 & 23 & 180 & 3 \\
\hline 4 & 28 & 180 & 3 \\
\hline 5 & 23 & 150 & 4 \\
\hline 6 & 28 & 150 & 4 \\
\hline 7 & 23 & 180 & 4 \\
\hline 8 & 28 & 180 & 4 \\
\hline 9 & 23 & 150 & 3.5 \\
\hline 10 & 28 & 150 & 3.5 \\
\hline 11 & 23 & 180 & 3.5 \\
\hline 12 & 28 & 180 & 3.5 \\
\hline
\end{tabular}

\section{TENSILE TEST RESULTS}

According to [2], the tensile strength test of the welded specimens was performed according to HRN EN ISO 68921:2016 [6] on the UHP40 testing machine located in the FESB laboratory in Split, whose maximum test force is 500 $\mathrm{kN}$. Prior to testing, all welded specimens were inspected visually using a microscope and $30 \times$ magnification (Fig. 5 and Fig. 6). The visual appearance of all samples was satisfactory.

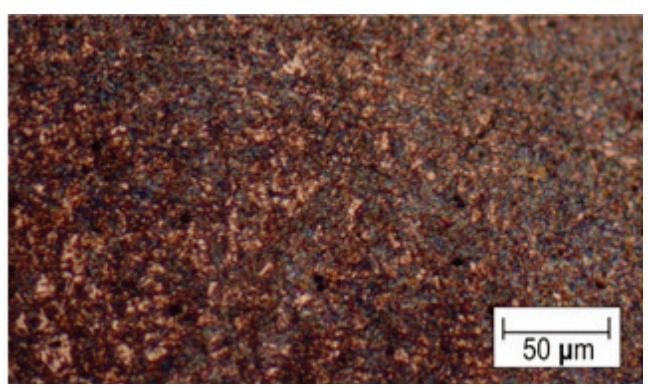

Figure 5 Microstructure of a $16 \mathrm{~mm}$ bar edge 


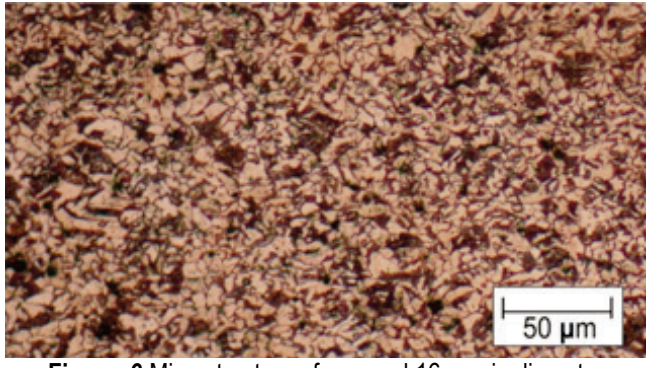

Figure 6 Microstructure of core rod $16 \mathrm{~mm}$ in diameter

The minimum and maximum test values obtained were omitted from the analysis, so that in Tab. 4 data for 10 specimens of $16 \mathrm{~mm}$ diameter rods are given.

Table 4 Test results for welded bars of $16 \mathrm{~mm} \mathrm{BSt} 420 \mathrm{~S}$ steel [2]

\begin{tabular}{|c|c|c|c|c|c|}
\hline Sample & Rod diameter & \multicolumn{3}{|c|}{ Variable parameters } & Tensile strength \\
\cline { 3 - 5 } number & $(\mathrm{mm})$ & $I_{\mathrm{w}}(\mathrm{A})$ & $F_{\mathrm{w}}(\mathrm{N})$ & $t_{\mathrm{w}}(\mathrm{s})$ & MPa \\
\hline 1.1 & 15.3 & 23 & 150 & 3 & 562 \\
\hline 1.2 & 15.3 & 23 & 150 & 3 & 566 \\
\hline 1.3 & 15.3 & 23 & 150 & 3 & 555 \\
\hline 2.1 & 15.3 & 28 & 150 & 3 & 531 \\
\hline 2.2 & 15.3 & 28 & 150 & 3 & 547 \\
\hline 2.3 & 15.3 & 28 & 150 & 3 & 556 \\
\hline 3.1 & 15.3 & 23 & 180 & 3 & 599 \\
\hline 3.2 & 15.3 & 23 & 180 & 3 & 609 \\
\hline 3.3 & 15.3 & 23 & 180 & 3 & 617 \\
\hline 4.1 & 15.3 & 28 & 180 & 3 & 656 \\
\hline 4.2 & 15.3 & 28 & 180 & 3 & 653 \\
\hline 4.3 & 15.3 & 28 & 180 & 3 & 620 \\
\hline 5.1 & 15.4 & 23 & 150 & 4 & 611 \\
\hline 5.2 & 15.4 & 23 & 150 & 4 & 637 \\
\hline 5.3 & 15.4 & 23 & 150 & 4 & 633 \\
\hline 7.1 & 15.3 & 23 & 180 & 4 & 559 \\
\hline 7.2 & 15.3 & 23 & 180 & 4 & 566 \\
\hline 7.3 & 15.3 & 23 & 180 & 4 & 573 \\
\hline 9.1 & 15.4 & 23 & 150 & 3.5 & 631 \\
\hline 9.2 & 15.4 & 23 & 150 & 3.5 & 635 \\
\hline 9.3 & 15.4 & 23 & 150 & 3.5 & 604 \\
\hline 10.1 & 15.4 & 28 & 150 & 3.5 & 593 \\
\hline 10.2 & 15.4 & 28 & 150 & 3.5 & 509 \\
\hline 10.3 & 15.4 & 28 & 150 & 3.5 & 511 \\
\hline 11.1 & 15.4 & 23 & 180 & 3.5 & 630 \\
\hline 11.2 & 15.4 & 23 & 180 & 3.5 & 643 \\
\hline 11.3 & 15.4 & 23 & 180 & 3.5 & 630 \\
\hline 12.1 & 15.4 & 28 & 180 & 3.5 & 603 \\
\hline 12.2 & 15.4 & 28 & 180 & 3.5 & 616 \\
\hline 12.3 & 15.4 & 28 & 180 & 3.5 & 595 \\
\hline & & & & & \\
\hline
\end{tabular}

\section{ANALYSIS OF THE TENSILE STRENGTH TEST RESULTS}

The processing of the results of the experiments was carried out using the software package "Design Expert". The software itself is an extremely powerful tool and is used both in the analysis of the results obtained and in the design of different experiments using different engineering, statistical methods and optimization of different processes. When using the program itself, it is important to choose one of the models offered and follow on-screen instructions. As the very experiment of this work was already planned by a three-factor test plan according to [2], Design Expert was used here only for the purpose of analyzing the results obtained, verifying the assumptions made in order to obtain optimal welding parameters which will result in the highest tensile strength of welded concrete steels.

A model with categorical factors was used for the analysis because according to [2] we have 3 factors that do not change continuously, so it is important to adjust the model to such factors. The results of the analysis are given in Figs. 7 - 11.

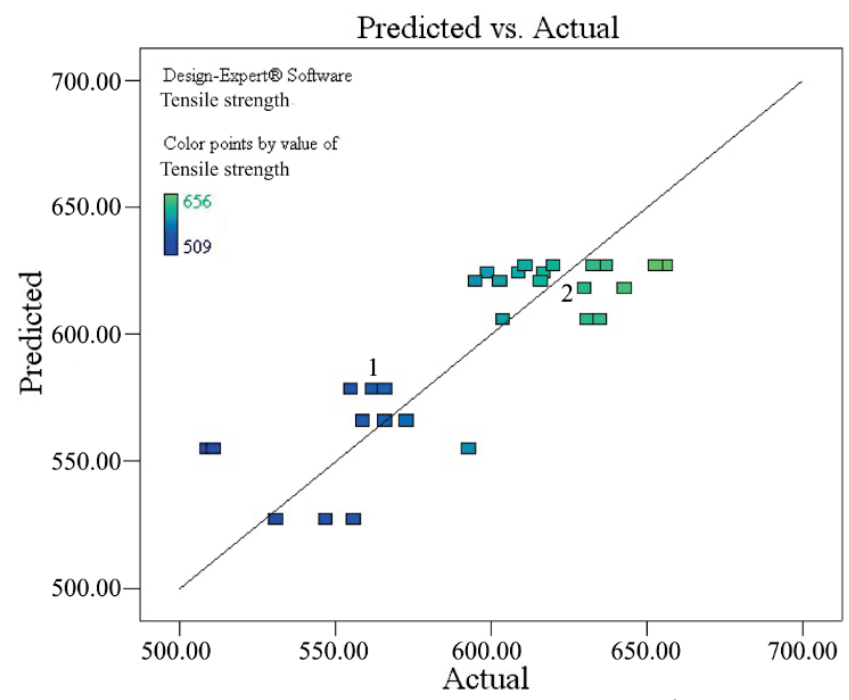

Figure 7 Relationship between obtained and predicted results of tensile strength values (in $\mathrm{MPa}$ )

In Fig. 7 the relationship between the actual and predicted tensile strength values according to the experimental results is shown. It is evident that the results do not deviate too much from the predicted ones, which shows us that both the model chosen and the results obtained are significant and further analyses of the obtained results can be carried out.

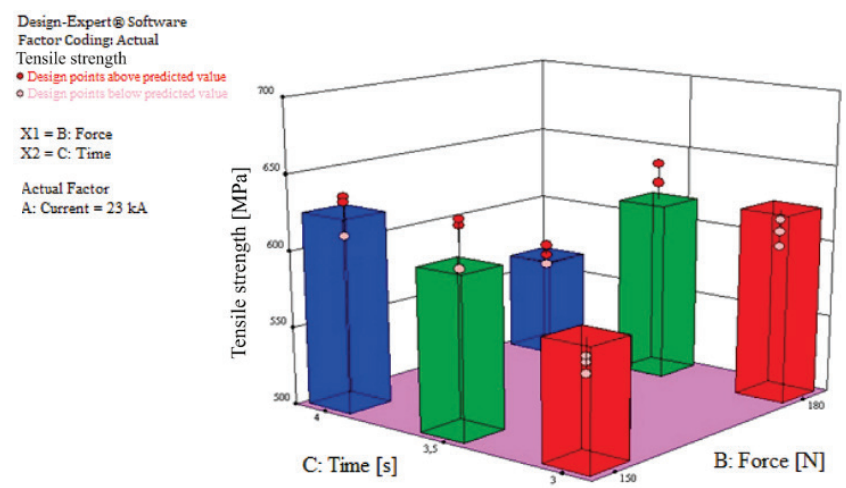

Figure 8 Effect of force and time on tensile strength at a constant current of $23 \mathrm{kA}$

Other Figs. 8 - 12 show the dependence of the tensile strength on different combinations of the observed welding parameters. 


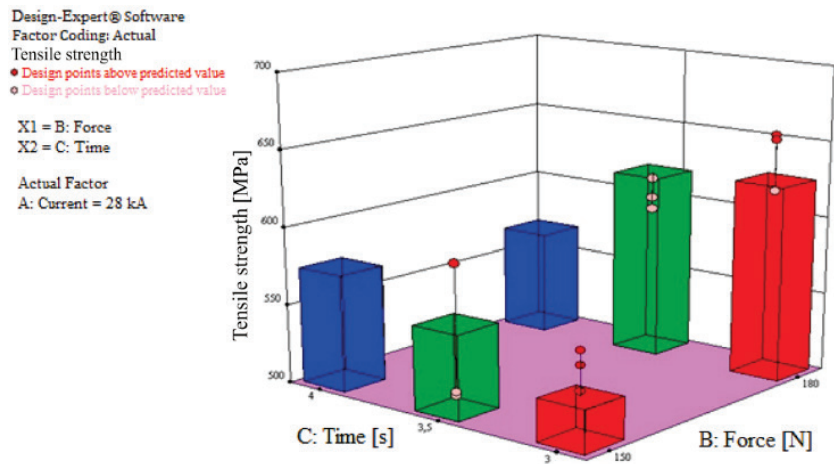

Figure 9 Effect of force and time on tensile strength at constant current of $28 \mathrm{kA}$

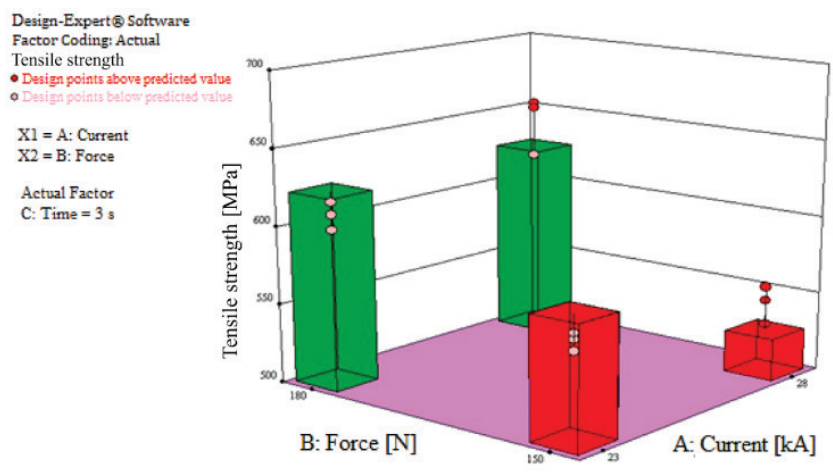

Figure 10 Effect of force and current strength on tensile strength at a constant time of $3 \mathrm{sec}$

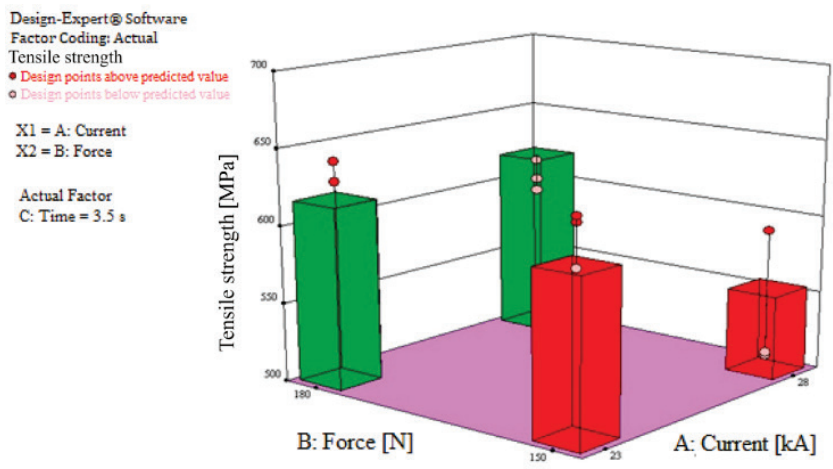

Figure 11 Effect of force and current strength on tensile strength at a constant time of $3.5 \mathrm{sec}$

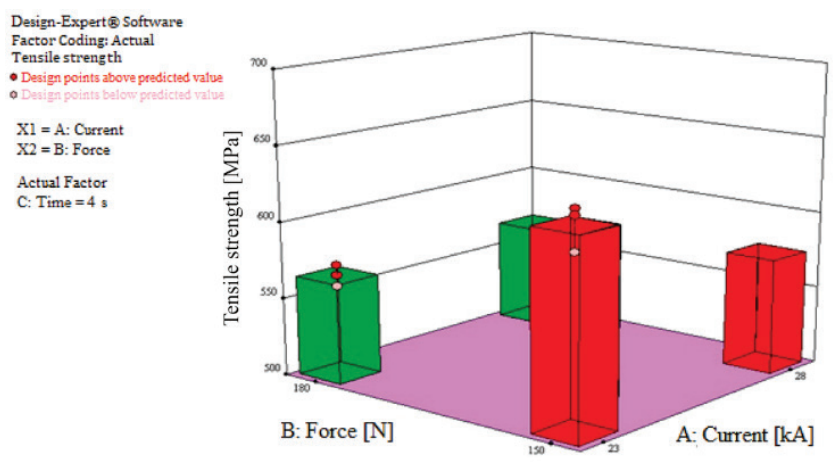

Figure 12 Effect of force and current strength on tensile strength at a constant time of $4 \mathrm{sec}$

\section{EXPERIMENT PLANNING USING THE "DESIGN EXPERT" SOFTWARE PACKAGE}

In this section an experiment plan for future research is made. The "Design Expert" software package was used - it offers a wide range of options for optimizing trial planning and processing data after experiments have been conducted, such as type and number of input parameters for a particular problem. This paper addresses the problem with three input parameters - time, force, current - and it selects a central composite test plan as one of the better models within the Design Expert.

After selecting the model of the test plan, it is necessary to enter the min and max values for each individual input parameter: force, time and current. Accepted parameters result the tensile strength as the output parameter. All parameters are entered into the central composite plan and shown in Tab. 5.

Table 5 Min and max values of input parameters [5]

\begin{tabular}{|c|c|c|c|c|c|c|}
\hline Name & Units & Type & Changes & Std. Dev. & Low & High \\
\hline Current & kA & Factor & Easy & 0 & 23 & 28 \\
\hline Time & s & Factor & Easy & 0 & 3 & 4 \\
\hline Force & N & Factor & Easy & 0 & 150 & 180 \\
\hline Tensile strength & MPa & Response & & & & \\
\hline
\end{tabular}

The next step is to design the experiment in such a way that Design Expert itself selects the required number of samples with different input parameters for each sample using the central composite model, Tab. 6 .

Table 6 Input parameters of each sample according to the central composite plan

\begin{tabular}{|c|c|c|c|c|}
\hline Std & Run & $\begin{array}{c}\text { Factor 1 } \\
\text { A: Current (kA) }\end{array}$ & $\begin{array}{c}\text { Factor 2 } \\
\text { B: time (s) }\end{array}$ & $\begin{array}{c}\text { Factor 3 } \\
\text { C: Force }(\mathrm{N})\end{array}$ \\
\hline 2 & 1 & 28 & 3 & 150 \\
\hline 17 & 2 & 25.5 & 3.5 & 165 \\
\hline 5 & 3 & 23 & 3 & 180 \\
\hline 12 & 4 & 25.5 & 4.3 & 165 \\
\hline 10 & 5 & 29.7 & 3.5 & 165 \\
\hline 15 & 6 & 25.5 & 3.5 & 165 \\
\hline 9 & 7 & 21.3 & 3.5 & 165 \\
\hline 6 & 8 & 28 & 3 & 180 \\
\hline 13 & 9 & 25.5 & 3.5 & 140 \\
\hline 1 & 10 & 23 & 3 & 150 \\
\hline 19 & 11 & 25.5 & 3.5 & 165 \\
\hline 3 & 12 & 23 & 4 & 150 \\
\hline 11 & 13 & 25.5 & 2.7 & 165 \\
\hline 4 & 14 & 28 & 4 & 150 \\
\hline 20 & 15 & 25.5 & 3.5 & 165 \\
\hline 16 & 16 & 25.5 & 3.5 & 165 \\
\hline 7 & 17 & 23 & 4 & 180 \\
\hline 14 & 18 & 25.5 & 3.5 & 190 \\
\hline 18 & 19 & 25.5 & 3.5 & 165 \\
\hline 8 & 20 & 28 & 4 & 180 \\
\hline
\end{tabular}

The model works in such a way that it always gives two values called the min / max limit for each input parameter; in this way it can be easier to ultimately optimize the process and give a better mathematical description of the problem depending on the input parameters.

Finally, it is necessary to perform experiments on the defaults for each sample and to enter the measured tensile 
strength results back into Design Expert, which then analyzes the results itself and gives the relevant mathematical polynomials and graphical representations of the tensile strength change depending on the input parameters, i.e. the force, time and current.

\section{CONCLUSION BASED ON TENSILE TEST RESULTS}

Electro-resistance welding is a specific technological process in which by varying the three parameters (current strength, compressive force and contact time) we obtain different values of the tensile strength on $16 \mathrm{~mm}$ concrete steel bar. For this reason, more experiments should be carried out and a universal mathematical model would be obtained which would result in optimal values of all three parameters in order to achieve maximum tensile strength.

Mathematical modeling of the butt welding process enables the prediction of optimal welding modes with respect to the dissipation of the value on a particular qualitative requirement at a constant welding mode, and the order of the welding parameters according to the influence on a particular qualitative request.

The models obtained are valid within the selected range of variation on welding parameters which must not be exceeded. This area can be relatively simple to determine based on existing tables and nomograms for selecting the welding mode, which often require only one combination of welding parameters.

The analysis of the obtained results has shown that the greatest influence on the tensile strength is due to the current strength and the compressive force during the buttwelding. The higher the current and pressure, the higher the tensile strength; however, then the contact time must be very low.

From all the above it is evident that this model is not satisfactory because the current strength and the compressive force are interdependent parameters, i.e. in order to achieve maximum tensile strength, both parameters must either increase or decrease and the contact time is inversely proportional.

In order to carry out the experiment to get a real state of affairs and an adequate mathematical model, immentation is recommended, but in this way, the experiment will be planned from the beginning with the help of the software package "Design Expert", which will ultimately lead to better results, more detailed and faster analysis of the obtained data and relevant mathematical models that can be used in real welding processes.

\section{REFERENCES}

[1] Dadić, Z. (2013). Cracks in Welded Joints. Seminar Paper, FESB, Split.

[2] Bilić, Ž. (2007). Optimization of weldability of ribbed concrete steel by controlling welding parameters. Master's thesis, FESB, Split (in Croatian).

[3] Kralj, S. (1992). Welding 1, Learning Script, FSB, Zagreb (in Croatian)
[4] Kordic, Z. \& Vucak, S. (1997). Electro-resistance Welding. School Book, Zagreb (in Croatian).

[5] Design Expert Software Pack

[6] HRN EN ISO 6892-1:2016. Tensile testing at room temperature - Method B.

Authors' contacts:

Željko Bilić

PPS -PROJEKTIRANJE d.0.0.

A. Mihanovića 31, 21000 Split, Croatia

pps@mail.inet.hr

Ivan Samardžić

Mechanical Engineering Faculty of Slavonski Brod,

Trg I. Brlić-Mažuranić 2, 35000 Slavonski Brod, Croatia

ivan.samardzic@sfsb.hr

\section{Nedjeljko Mišina}

Faculty of Electrical Engineering, Mechanical Engineering and Naval Architecture, R. Boškovića bb, 21000 Split, Croatia

nedjeljko.misina@fesb.hr

\section{Katarina Stoić}

Strojarska tehnička škola Frana Bošnjakovića, (Engineering Technical School Fran Bošnjaković), Konavoska ulica 2, 10000 Zagreb, Croatia stoic.katarina.93@gmail.com 